\title{
In the Shadow of Doubt
}

Sebastiano D'Urso

University of Catania

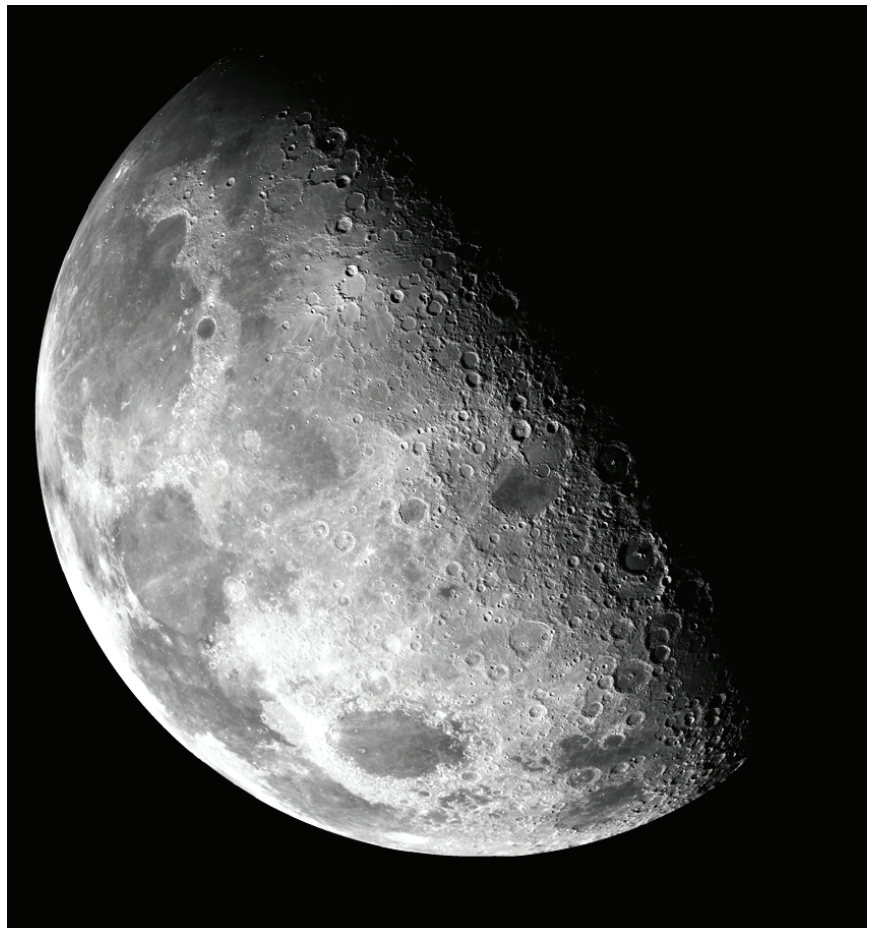

Figure 1. The moon.

I would like start by showing the moon half in light and half in shadow since teaching architecture is like pursuing a sphere that always has one side in the shadow of doubt. Architecture, like the moon, offers its unexplored side to the curiosity and imagination of those who feed the desire for knowledge with doubt. However, learning architecture is like pursuing the same sphere that always has a side in the light of doubt. And in point of fact, even the side in light, the side that is believed to be already known, always offers many ideas for new reflections and knowledge. Both the particular circumstances are characterized by: pursuing something very difficult to achieve fully; the value of the pursuit of an object, the sphere that here represents architecture but which, among many other things, also represents infinity; the doubt that affects teaching and also research.

The light side represents the knowledge already acquired. However the history of science shows that this knowledge can be challenged by new discoveries and theories. The side in shadow instead must be discovered with great courage and curiosity. The symbolic value of the sphere is linked to architecture both as it has been declined by the masters of the past (Boullée and Ledoux among all) and for the universality of the form. Moreover, the sphere represents perfection. In fact in the multidimensional tale of Abbott, the sphere represents the supreme master because it is the perfect form. Doubt is that condition that can affect both teaching and scientific research, as we will try to argue below.

Cultivating the attitude to doubt both in teaching and in the profession of architecture does not want to push towards the sphere of uncertainty or controversy. This is not scepticism or postmodern 
relativism but a sort of doubt concerning methodology. Doubt as a method of knowledge is not a novelty. The Cartesian method of doubt in the search for truth is based on the proposition: de omnibus dubitandum est. In fact, thinking for Descartes gives substance to human existence - ego cogito, ergo sum, sive existo ${ }^{1}$ - and thinking also means doubting. Several philosophers and thinkers, before and after Cartersio, will rely on doubt as a method of knowledge of reality: cognitive doubt. Socrates asked questions of his disciples and claimed that he did not know the answers. The aim of the Greek philosopher was to subject the preconceived notions and beliefs of the time to substantial doubt. Francis Bacon adopts a scientific methodology based on doubt to dismantle what he calls "idola": false truths that prevent knowledge of reality and that for this reason must be subjected to a systematic doubt. Karl Popper contrasts verification with falsification in scientific research. He claims that the results of the research should not be subjected to verification but to falsification, that is: "show me where my hypotheses and theories are wrong" ${ }^{2}$. Also in this case doubt is the basis of the development of knowledge. Kierkegaard ${ }^{3}$, by contrast, finds that doubt cannot be the basis of knowledge because it is a form of reaction to knowledge built by others. Kierkegaard argues that doubt is never positive but negative. Doubt is an answer and not a proposal. Due to this reason he prefers amazement which, unlike doubt, has a positive meaning. Probably "doubt is one of the names of intelligence", as Jorge Luis Borges said, if it is associated with curiosity and irony, understood as the ability to question oneself and to put question. Human intelligence and knowledge are based on doubt. In fact, if for every step of the construction of knowledge there had been no one who had questioned - doubted - the presumed truths of the time, today we could believe that the earth is flat and that the sun goes around it. And yet today there is someone who has begun to doubt that this is indeed the case. An analysis of the consequences to which doubt can lead is carried out, although with different objectives and tools, by both the philosopher Davide Miccione and the scholars Peter Berger and Anton Zijderveld.

Peter Berger and Anton Zijderveld make a synthesis of doubt and wonder as faces of modernity ${ }^{4}$. That same modernity that the philosopher Davide Miccione calls hypermodernity 5 . One of the consequences of this hypermodernity is what Miccione calls "cognitive underproletariat": hypermodern ignorant who, from the height of his non-knowledge, doubts knowledge without basing his doubt on anything other than the possibility of being able to express it. That is, he does not doubt because he knows but he doubts because he does not know. This increasingly widespread condition, according to Miccione, belongs to the hypermodern society and is one of the risks entailed by doubt.

Berger and Zijderveld praise doubt in the era of pluralist modernity (the same one indicated by Miccione but called by a different name). They argue that harboring doubt can save man from fanaticism but also and paradoxically from extreme relativism and cynicism. The paradox is that cynicism and extreme relativism can be derived from doubt. They also recognize that "doubt is ... a high-risk subject" since it can lead to paralysis of decisions - as in the example of Buridano's donkey - and to cognitive insecurity. It can degenerate into despair and hopelessness and into the loss of confidence in ourselves. Berger and Zijderveld, to avoid the perpetration of postmodern relativity and to better squirm in modern pluralism and fundamentalism, propose seven "Prerequisites for any future vision of the world that wants to present itself as an intermediate position between relativism and fundamentalism"7. The following points take on particular significance for our reflections: "3. A refusal of relativism to balance the rejection of fundamentalism "; "4. The acceptance of doubt as having a positive role in the community of particular faith "; "5. A definition of "others" that does not categorize them as enemies "; "6. The development and maintenance of civil society institutions that allow peaceful debate and conflict resolution "; "7. The acceptance of "choice", not only as an empirical fact but as a morally desirable fact"

Each of these brief considerations on doubt can be transferred to the teaching / learning of architecture. In architecture, understood as a form of knowledge and not only as knowledge of the form, doubt can be a horizon to be explored both for those who teach and for those who learn.

Architecture is very complex although it has been dismembered in many teachings. In fact, for the relationships with the social, cultural, environmental, economic, territorial context, and so on, architecture needs a holistic and complex vision. Doubts, faced with so much complexity, are inevitable and perhaps also indispensable to be able to deal with one's own activity with awareness and responsibility. Therefore someone says that, at this moment, school has to give the right to doubt? . The right to doubt means the right to amaze with questions that can break barriers. The right to remember that there are more mysteries than problems and that abstention from conformist judgment can be taught.

On the other hand, our time requires certainties disguised as competences and specializations. Contemporary society wants more and more super specialized individuals who cannot have doubt. Otherwise, they would not be efficient. In other words, "a hyper-cognitive model prevails today that would like to emancipate itself completely from value concerns, to reinforce the competence to solve problems rather than knowing how to pose them"10. It is not by chance that "the hypermodern ignorant, more simply, asks himself no question about the functioning of reality"11. And this is because, according to Miccione, "the world as an object of knowledge is fading" 12 for the benefit of virtual socialization platforms. And extreme fundamentalism or relativism reigns in these platforms. The most alarming thing about this panorama described by Miccione is what defines "the anti socratic element, the not knowing not to know, and not being interested in knowing it"13.

The condition of today's society, according to the philosopher Zygmunt Bauman, sees knowledge in a state of "permanent revolution". While "the invariable goal of education was, in every age is and will remain, the preparation of these young people for life in the realities in which they are destined to enter"14. In the condition of "permanent revolution" of knowledge in the modern era - or it would be better to say hypermodern - Bauman therefore sees sufficient transformative powers capable of changing the current educational system 
for the better.

School, in every degree including university, is following this chimera or this drift.

All this to the detriment of whom? If it is true that the super specialists are able to find work immediately, what will happen to them when their expertise will no longer be of use? And in our age, change is always faster. Will they be able to change their certainties (competences) with the same speed and re-enter the labor market? Or will they be discarded in favor of new expertise? Is what is essential today the discard of tomorrow? We hope to be wrong, but we have some doubt. What to do to prevent this, hopefully remote, possibility? Continue to pursue the labor market that chooses the specializations but, paradoxically, appreciates versatility and flexibility? Or continue to cultivate doubt as a method of knowledge and therefore also of professional practice? What advantages can the choice of doubt as a method bring? And what disadvantages does it involve? Is perhaps doubt still the method to be pursued to try to understand the complexity of architecture rather than certainty?

Doubt as a sign of curiosity. Doubt as a search for responsibility. Doubt as a search for new solutions. Doubt as a investigation of tradition but also of innovation. Doubt to overcome our limits. Doubt as a void yet to be filled. Doubt as hope to overcome modern contraposition of science education versus aesthetic education. In these terms all the questions posed up to now would seem to be rhetorical. Or maybe not?

Marco Vinicio Masoni, an Italian psychologist and psychotherapist who has written a lot about pedagogy, moves in this direction when he says that "knowing everything that is declared true may not even be, knowing that I can discuss, undermine, improve, criticize, that there is no absolute. I can know this. I don't know how to do it, I'm defending myself with the veil of ignorance. But I know this should be done. I know that if I taught musical doubt I would build musical thought. I believe this is the richness of the didactics of doubt"15. Masoni, with humility and coherence, says he does not know how to do but to know that doubt is essential to improve knowledge. However, the Italian scholar points out that to doubt what is declared true it is first necessary to know it. In fact, it is possible to discuss, put into crisis, improve or criticize only by knowing. Masoni knows this. What he doesn't know is how to do it. He also has doubts about how to do it. Instead, he knows, and shows it in his writings, that for example he could have built musical thought with the teaching of musical doubt. And this can be done in every field of human thought and knowledge. One could immediately apply it to our field of knowledge and say that if we could teach architectural doubt we could construct architectural thought.

In fact, teaching in the shadow of doubt is not a method. It is rather a kind of attitude, almost an approach. The methodological drift has the risks that Donaldo Macedo identifies: "critical educators should at all costs avoid short-sightedly embracing approaches that express only formal adherence to democracy, and should instead always be open to a multiplicity and variety of approaches that can increase the possibility of an epistemological curiosity for the object of knowledge"16. In this way also "dialogic teaching - according to Paulo Freire - ceases to be a real process of learning and knowledge and instead becomes mere formalism"17.

This goes hand in hand with the teaching of a method that can be completely sterile if it is accepted uncritically. Instead, in agreement with Randy Pausch, the task of a teacher is to educate his students to know how to judge themselves ${ }^{18}$. This is possible only by questioning one's own results, even when they seem excellent. However, no method and no self-assessment can replace the pleasure of knowing. This latter corresponds to curiosity, to desire since, as the psychoanalyst Massimo Recalcati says, it is "the desire to know as a condition of every possible knowledge"19. However curiosity and desire alone are not enough. Recalcati has learned from one of his fundamental teachers for his own education that "desire without commitment is only a whim and insecurity increases with knowledge and not vice versa, because there is no knowledge that it can fully absorb life, because authentic research increases doubts without ever claiming to solve them" 20 . Here doubt is the protagonist of all knowledge.

The effort to build an architectural thought by teaching architectural doubt faces with the complexity of architecture and in particular of the architecture taught at the university: "architexity"21. Doubt as a calling into question and criticism of architecture has always been the approach that led to new styles and languages in architecture. Doubt that in the disciplinary field also derives from multiple inputs. Inputs that are often dichotomous as are the following: time/space; material/ dreams; technologies/philosophies; order/chaos; program/event; traditions/contradictions; science/utopias; geometries/ambience; ambiguity/simplifications; processes/signs; virtual/globalization; context/ content/concept; form of knowledge/knowledge of form; organic/ inorganic; autopoietic/autonomic; automation/participation; physiological/meteorological; biological/computational; parting/cooperation et cetera. However these dichotomies are not enough to describe the complexity of the architecture. In fact, there is an infinite variety of nuances between the opposites of every dichotomy. It is not always so easy to understand that the complexity of reality is difficult to represent. Representing reality through complementary opposites can be useful but it is always reductive. It leaves little room for doubt.

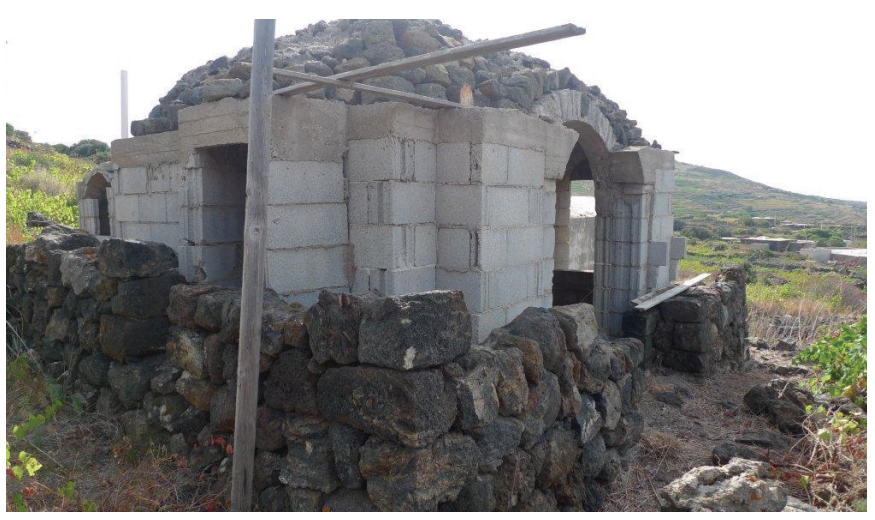

Figure 2. Taditions/contraditions. This typical construction of the islands of Pantelleria and Lampedusa is called dammuso. Originally built in stone and today instead clad in stone. 

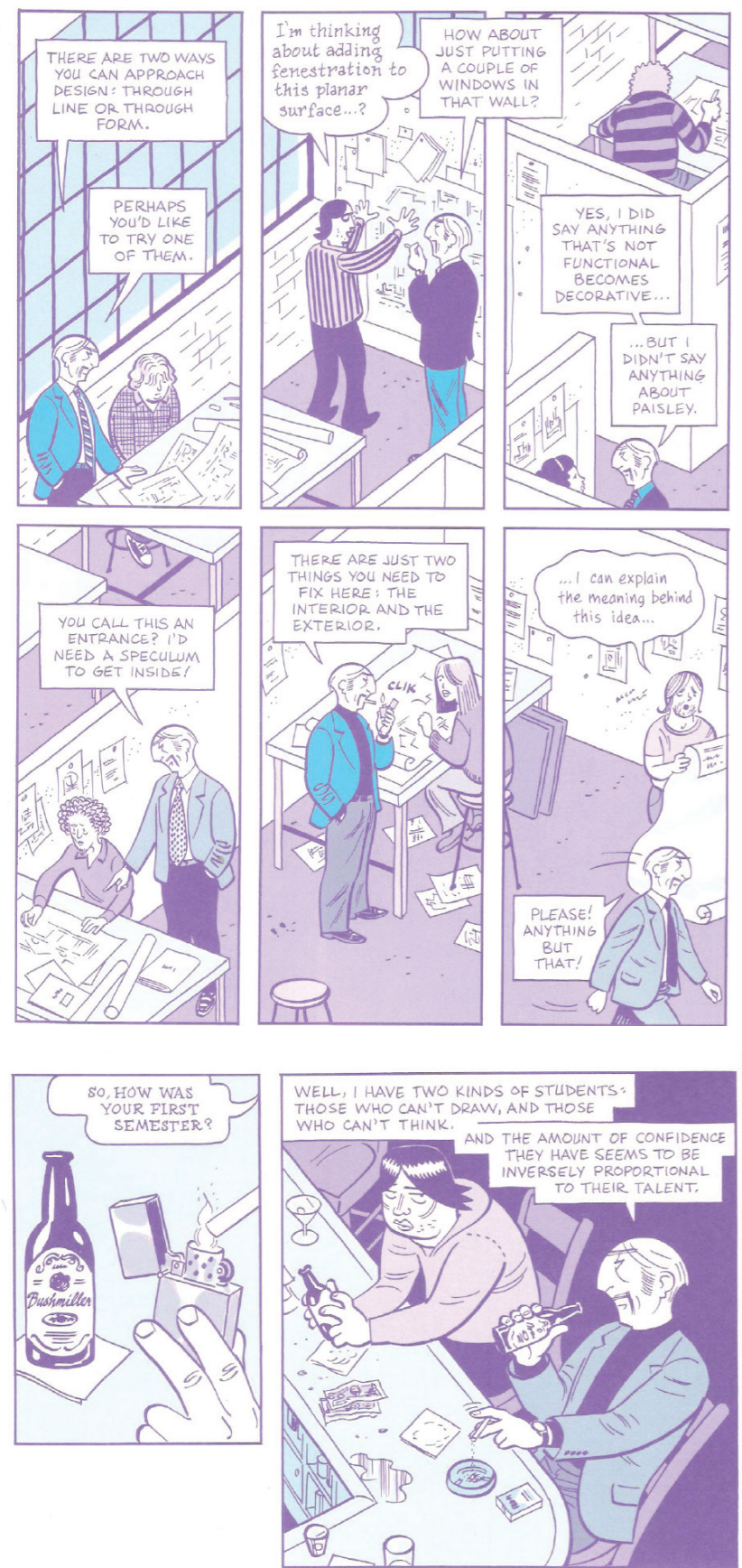

Figure 3. Asterios Polyp by David Mazzucchelli.

What kind of teaching is Asterios Polyp's? And what kind of learning is that of his students? Asterios Polyp, before classifying his students in two major categories, could also ask himself what kind of professor he was. David Mazzucchelli, author of the graphic novel, succeeds in making a portrait of the professor of architecture clear and full of food for thought. Asterios Polyp is a professor but above all a person who never seems to have doubts: he represents reality according to schemes made up of categories of opposites. The encounter with the woman who will marry and will soon be separated opens the way to doubt. He will finally understand that "the world, the real one, the natural one, is much richer and more complex than the oppositional schematism - "either/or" - that our anthropocentric culture has imposed on it"22. The graphic novel by Mazzucchelli shows how even pop culture notes the same need to start again from doubt as an approach to knowledge.

In the light of this, the personal experience of teaching architecture with the approach of doubt was addressed. The answers to the students' questions are almost always other questions. This is because the solutions were never imposed on the students but they found their solution, knowing that it was not the only or the best solution. There is always time to improve if you recognize your momentary limits. Recognizing one's limits is in fact the first step to overcome them. At least $\mathrm{i}$ think so. The simplest limit to overcome is often laziness. In order to do this i always ask the same question, the first question: why are you doing this? They often don't know how to answer this simple question. The question is indeed upsetting because the student automatically repeats what he has learned to do up to that point. But when they try to answer this first question, a world of possibilities opens up. When they find their answer, that world of possibilities becomes a common heritage both of those who teach and those who learn. Everything comes from this simple question: why do you do what you do? This involves other questions like: how would you do it? What is the problem you are trying to solve? Which tools are you most comfortable with? And their answers are always a great teaching.

Some students, those seeking certainty, remain disoriented by this approach and continue to prefer the path tested by their precursors. They do not question themselves and automatically repeat actions and procedures. They will not be bad students for this but i would be a bad teacher if i did not offer them the opportunity to think for themselves. This is because i learned from them that just when you think you have all the answers, life changes the questions.

"An unspeakable horror seized me. There was a darkness; then a dizzy, sickening sensation of sight that was not like seeing; I was a Line that was no Line; Space that was not Space: I was myself, and not myself. When I could find voice, I shrieked aloud in agony, "Either this is madness or it is Hell." "It is neither," calmly replied the voice of the Sphere, "it is Knowledge; it is Three Dimensions: open your eye once again and try to look steadily" 23 .

The wonder that captures the Square - the geometric figure and the protagonist character of Flatland by Edwin Abbott - is that of someone who had never doubted his own reality and who suddenly has access to a new dimension that was previously unknown. From that moment on, one's life can no longer be the same, even if one wishes. It is not a question of having acquired a method of knowledge based on the doubt that there may be other unknown realities. Instead, it is a matter of feeding the curiosity that underlies all knowledge with an existential, almost ontological doubt. In this way i would like to conclude by answering perhaps more precisely a question posted to me during the presentation at the conference in Antwerp: once 

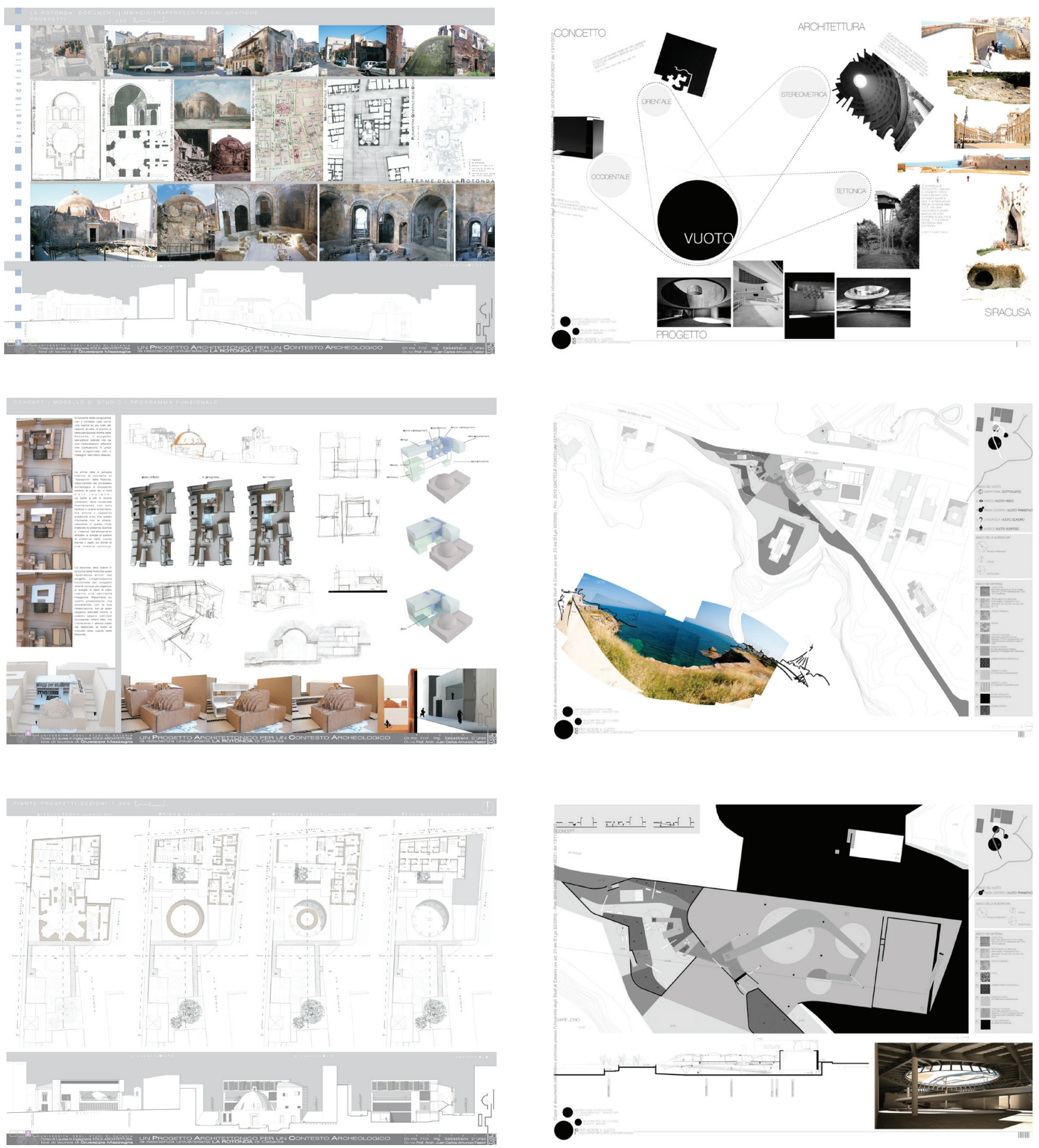

Figure 4. This is the thesis of Giuseppe Mazzaglia one of my students with whom we have cultivated a lot of doubt before intervening in a site next to Roman baths.

Figure 5. This other thesis is by Alfio Giardina, another student of mine. To Alfi 's questions i have always answered with other questions. Alfio designs an urban park and cultural and sports center in the archaeologica quarries of Syracuse. 
doubt has made its way through our certainties it is impossible to go back. It is not a question of applying a method like another which, only as a matter of convenience or fashion, has the name of doubt. I do not apply a method of doubt, but every day i have doubts to let myself be surprised by life. In this way i hope to be able to instill the germ of doubt even to those who, for different reasons (student, friend, or family member), i meet in my path.

In conclusion i would like to underline that doubting something requires that this something is more than well known. We can therefore say: what is wrong with doubting whether by doubting, in a conscious and correct way, we can, if not discover new things, at least deepen more what we know?

\section{Notes}

1. Cartesio. Discorso sul metodo. (Milano: Mondadori,1993), 90.

2. Karl Popper as quoted by Peter Berger and Anton Zijderveld. In Praise of Doubt: How to Have Convictions Without Becoming a Fanatic. (New York: HarperCollins Publishers, 2009), 100.

3. Soren Aabye Kierkegaard. Johannes Climacus. Orde omnibus dubitandum est and a sermon. (London: Adam and Charles Black, 1958).

4. Berger and Zijderveld. In Praise of Doubt, 101.

5. Davide Miccione. Lumpen Italia. I/ trionfo del sottoproletariato cognitivo. (Milano: IPOC, 2015).

6. Berger and Zijderveld. In Praise of Doubt, 128.

7. They refer to the writing by Immanuel Kant.Prolegomena to Any Future Metaphysics that will be able to come foward as science.

8. Berger and Zijderveld. In Praise of Doubt, 105-107.

9. Marco Vinicio Masoni. Scuola e destino. Verso una didattica del dubbio. (Milano: Fabbrica dei Segni, 2018), 165.

10. Massimo Recalcati. L'ora di lezione. Per un'erotica dell'insegnamento. (Torino: Einaudi, 2014), 14

11. Miccione. Lumpen Italia. 25.

12. Miccione. Lumpen Italia. 32.

13. Miccione. Lumpen Italia. 51.

14. Zygmunt Bauman. Conversazioni sull'educazione. (Trento: Erickson, 2012), 31.

15. Masoni. Scuola e destino. 165.

16. Paulo Freire and Donaldo Macedo. Cultura, lingua, razza. Un dialogo. (Udine: Forum, 2008), 28.

17. Freire and Macedo. Cultura, lingua, razza. 29

18. Randy Pausch with Jeffrey Zaslow. The last lecture. (New York: Hyperion, 2008).

19. Recalcati. L'ora dilezione. 65.

20. Recalcati. L'oradilezione. 139-140.

21. The word "architexity" is the crasis of architecture, complexity and university. For further information please read: Sebastiano
D'Urso. "Imparare l'architessità?". In / confini del progettare. seminari sull'architettura, l'uomo e la bellezza, edited by Sebastiano D'Urso, 15-46. Caltagirone: letteredaQALAT, 2015: Sebastiano D'Urso. "L'inevitabile complessità dell'architettura". In Processo alla complessità, edited by Giuseppe Sapienza, 51-71. Caltagirone: letteredaQALAT, 2015; Sebastiano D'Urso. "Insegnare l'architessità?". In La formazione dell'architetto. Problemie prospettive. Attidel IV Forum dell'associazione nazionale dei docenti di progettazione /car 1415 16, edited by Manuela Raitano, 26-29. Roma: Calameo, 2015.

22. Francesco Vitale. "Asterios Polyp (Mitografie della decostruzione). In Pop filosofiaedited by Simone Regazzoni, 127-139. Genova: II Melangolo, 2010

23. Edwin A. Abbott. Flatlandia. (Torino: Bollati Boringhieri, 2008), 186-188. 